\title{
Towards a Theory of Constrained Relativism: Comparing and Combining the Work of Pierre Bourdieu, Mary Douglas and Michael Thompson, and Alan Fiske
}

\author{
by Marco Verweij \\ Jacobs University Bremen
}

\author{
Sociological Research Online 12(6)7 \\ <http://www. socresonline.org.uk/12/6/7.html> \\ doi:10.5153/sro. 1595
}

Received: 13 Oct 2006 Accepted: 20 May 2007 Published: 30 Nov 2007

\begin{abstract}
In this article, I seek to compare Pierre Bourdieu's theory of practice, the cultural theory developed by Mary Douglas and Michael Thompson, and the relational models theory pioneered by Alan Fiske, and attempt to sketch how these theories could possibly be combined. I argue that the three theories are among the most interesting conceptual enterprises in the social sciences of the last few decades, as they all represent -quite similar-syntheses of long-standing social-science dualisms, such as objectivism vs. subjectivism, social structure vs. free will, functionalism vs. social conflict, etc. Besides these commonalities, I spell out the relative strengths and weaknesses of each of these approaches. This allows me to conclude by considering whether, and how, it might be possible to synthesise these syntheses by picking the most interesting features of the three theories, and avoiding their less appealing ones.
\end{abstract}

\section{Introduction}

1.1 During the last thirty years, three valiant attempts have been made to construct novel, general social and political theories by carefully considering, criticising and synthesising the "classics" of social and political science: the works of Marx, Weber, Pareto, Durkheim, Mauss, Malinowski, Evans-Pritchard, LéviStrauss, Piaget, Parsons, etc. These ambitious efforts have been undertaken by: French sociologist Pierre Bourdieu - in developing his "theory of practice"; British anthropologists Mary Douglas and Michael Thompson - through formulating their theory of socio-cultural viability (better known as "cultural theory"); and American anthropologist Alan Fiske - with his "relational models theory". [1] In this article, I will try to perform the same operation (or, rather, a miniature version thereof) that these theorists have performed on the canonical writings of social science on their own works. That is to say, I will attempt to compare and criticise these three theories, and will also consider how -by picking the most interesting features of these theories and avoiding their less appealing ones- a synthesis might be forged. This operation will consist of four simple procedures. First, I will spell out the various similarities between Bourdieu's theory of practice, the cultural theory of Douglas and Thompson, ${ }^{[2]}$ and Fiske's relations models theory. This will reveal the sheer ambition and creativity that has driven these attempts at building general social and political theory. Thereafter, I will highlight the weaknesses of each of these frameworks, before I list their comparative advantages and strengths. On the basis of all that, I will conclude by attempting to sketch what a synthesis (which I propose to call "a theory of constrained relativism") might look like, and which steps might need to be taken to arrive at such a synthesis. [3]

\section{Similarities}

2.1 One feature, more than anything else, unites the research of Pierre Bourdieu, Mary Douglas and Michael Thompson, and Alan Fiske, and makes it stand apart from other forms of theorising during the last few decades (such as rational choice-theory, post-structuralism, critical theory, world systems theory, the theory of risk society, or general systems-theory). ${ }^{[4]}$ This is their refusal to choose sides between the opposing camps in the various, centuries-old conceptual battles of the social sciences. These four researchers have all attempted to construct general theories that are syntheses of the dualisms and dilemmas that have prevailed in the social sciences. This of course also implies that the theories of our four authors are deeply rooted within the history of the social sciences. Indeed, these researchers have all attempted to overcome many of the dichotomies of the social sciences by criticising, reconsidering and recombining the canons of social theory. In their own words: 
Authors -Marx, Durkheim, Weber, and so on- represent landmarks which structure our theoretical space and our perception of this space. The difficulty of sociological writing stems from the fact that you have to struggle against the constraints inscribed in the theoretical space at a given moment - and especially, in my case, against the false incompatibilities that they tend to produce (Bourdieu 1990a: 30).

One way of describing Cultural Theory is to say that it is a programme for the extermination of dualisms (Thompson 1996: 49).

My hope in writing this book is to show that social scientists have independently discovered bits and pieces of something that can only be understood when we bring the fragments back together and reconstruct the whole from which they come (Fiske 1991a: vii).

2.2 Although each scholar goes about this in his or her own way (with Bourdieu taking relatively more from the works of Marx, Douglas and Thompson seeking to build more on the ideas of Durkheim and EvansPritchard, while Fiske puts somewhat more emphasis on Weber and Piaget), this shared ambition to overcome the ancient dilemmas and divisions of social science is the main source of the many similarities between their theories.

2.3 A first such commonality is the attempt to provide a synthesis of the long-standing opposition between objectivism and subjectivism. Social scientists have often been split between those who have held that social life is governed by the law-like interaction of objective (that is, non-mental) forces, and those who have assumed that social life is instead determined by people's ideas, values and perceptions (i.e., their subjective states) that defy any attempt at generalisation. In other words, a common assumption has been that if one wanted to generate valid, scientific knowledge about social life, then it would be fruitless to focus on "subjective" factors, such as perceptions, norms, and ideas. Not so, according to our authors:

Of all the oppositions that artificially divide the social sciences, the most fundamental, and most ruinous, is the one set up between subjectivism and objectivism (Bourdieu 1990b: 26).

Our view is that this rigid dichotomy between interpretation of meaning and scientific explanation is unjustified. It is true that human beings create meaning. But it is also true that it is possible to make statements of regularities that help in explaining and even predicting (or retrodicting) the human construction of meaning. Subjectivity need not rule out regularity as long as different sorts of people feel subjective in similar ways regarding similar objects (Thompson, Ellis and Wildavsky 1990: xiii).

[My Structures of Social Life] was also implicitly an argument with the relativistic cultural constructionists... I hoped (futilely, no doubt) to convince them that it was possible for universal evolved mechanisms to generate cultural diversity and uniqueness - and to show why (Fiske 2004a: 19).

2.4 All four theorists attempt to resolve this old conundrum by spelling out ways in which people's thoughts, assumptions and perceptions are linked with, and are constrained by, ways of structuring human interaction. In the theory of practice (Bourdieu 1977: 72), a particular "social structure" gives rise to a specific "habitus" (i.e., "a system of durable, transposable dispositions"), which serves to fortify that social structure. In cultural theory, five "ways of organising social relations" induce four "cultural biases" (including views of nature, human nature, time, space, risk, blame and justice, besides many other predispositions), which justify and underpin those ways of organising social relations. In relational models theory, four "mods" (fundamental models for social interaction) are complemented by "preos" (consisting of "paradigms, parameters, precepts, prescriptions, propositions, and proscriptions" - Fiske 2004a: 4). In insisting that the fundamental categories of human thought are shaped by -and, in their turn, shape- different social structures, all the authors follow the main thesis of Durkheim's The Elementary Forms of Religious Life (1912/1985).

2.5 Another social science-dualism that these authors strive to overcome concerns the question whether people's behaviour is determined by collective forces or by personal decisions: is society the outcome, or the source, of individual predispositions and actions? Again, our four authors argue that this is a conceptual non-starter. In their view, any social theory worth its salt needs to make room for both social determination and individual initiative, and needs to spell out their possible mutual relationships. Essentially, the authors make two claims. First, they assert that social structures never fully determine people's choices, but merely constrain them. They compare social structures to the rules of a game, which can be bent, disputed and followed in different ways, and which leave plenty of room for alternative game plans. In addition, they argue that although people's social relations provide them with their basic categories of thought (such as views of time, space, human nature, causation), individuals remain capable of critically reflecting upon, and comparing, their social conditions and the empirical validity and practical value of their own assumptions - and thus of bringing about social change. Therefore, as one cultural theorist puts it:

It is individuals as social creatures that, not only being moulded by but actively moulding their social context -shaping the maze as well as running it- that are the focus of cultural theory (Wildavsky 1987: 7).

\subsection{Compare this to:}

Habitus is not the fate that some people read into it. Being the product of history, it is an open system of dispositions that is constantly subjected to experiences, and therefore 
constantly affected by them in a way that either reinforces or modifies its structures. It is durable but not eternal! (Bourdieu and Wacquant 1992: 133).

\subsection{And to:}

The relational models do not fully specify behaviour in any interaction or situation, but they comprise a set of rules that strongly constrain the possibilities and that organize responses to violations of the rules (Fiske 1991a: 21).

Relational models theory argues that [..] people are thinking about the structures and processes of interaction. People are intensely concerned and deeply knowledgeable about relationships in their own right [..]. We care about and cognize equality, balance, hierarchy, shared communal identity, and so on (Fiske and Haslam 2005: 282).

2.8 The next red herring across which Bourdieu, Douglas and Thompson, and Fiske collectively leap concerns the debate whether either "values" or "self-interests" are the prime movers of social life.

2.9 They have all pointed out that these concept are often left undefined in social and political science, merely to be used in a tautological manner (Bourdieu and Wacquant 1992: 116-17; Douglas 1987: 24-25; Schwarz and Thompson 1990: 49; Fiske 1991a: 384-7). That is to say, by not defining and delimiting such notions as norms, values and interests, it becomes possible to always claim that whatever actions people have engaged in was the result of their adherence to some norm, value or perceived self-interest (cf., Sen 1977; Hirschman 1992). Rather than confining oneself to this distressingly small circular loop, the authors point out that it makes more sense to conceptualise the origins, and content, of people's norms and perceived interests. In their view, as I already mentioned, social structures determine to a significant degree people's fundamental categories of thought, such as their notions of time, space, human nature, justice, causation, honor, etc. Taken together, these predispositions shape what people perceive to be the overriding goals (or interests) that they should be striving for, the legitimate and illegitimate strategies for doing so (i.e., the norms and values that they should keep in mind), and what constitutes and confers status and power in particular situations. Thus, in their view, people's values and norms are just different elements of their habitus (to use Bourdieu's concept), cultural bias or cosmology (to invoke the terms of cultural theory), or interaction models (in Fiske's phrase).

2.10 Yet another dichotomy that is conspicuously absent in the theory of practice, cultural theory and relational models theory is the one between modernity and pre-modernity. Mary Douglas's classic precursor to cultural theory, Purity and Danger (1966), is explicitly written against the old division of the world in parts that are primitive, pre-modern, magical, superstitious, religious, irrational and pre-scientific, and those that are advanced, modern, secular, rational and scientific. (She blames an earlier social science-classic, The Golden Bough: A Study in Magic and Religion by the anthropologist Sir James George Frazer (1922/1995), for popularising this distinction within academia.) Indeed, it is possible to characterise the entire research of Douglas as an effort to show that the actions, emotions and perceptions of human beings have always been shaped by social structures and cultural biases - no matter where and when their lives unfolded. Thompson followed up on her lead, showing -in articles such as "Fission and Fusion in Nuclear Society' (1980); "Among the Energy Tribes" (1984); and "How to Save the Himalayas When You Cannot Find out What's Wrong with Them" (1985) - that the policy - making and scientific elites in the fields of energy provision and development assistance can be as (if not more) blinkered as anyone, including the Nepali villagers they are supposed to advise. Very much the same applies to the frameworks of Bourdieu and Fiske. In their view, too, all people are rational, creative and reflective individuals that are constrained, motivated and directed by their social relations:

Social agents, in archaic societies as well as in ours, are not automata regulated like clocks, in accordance with laws which they do not understand. In the most complex games, matrimonial exchange for instance, or ritual practices, they put into action the incorporated principles of a generative habitus (Bourdieu 1990a: 9; emphasis added).

The broadly consistent pattern of results across American, Bengali, Chinese, Korean, and Vai subjects suggests that the four relational models are not etnosociological folk concepts derived from any particular culture. They are implicit schemata people use in diverse and widely dispersed cultures - perhaps all cultures. Different cultures use the same models in different domains and implement them according to different parameters, but the underlying models are the same (Fiske 1993: 491).

2.11 It is no coincidence that the first, rudimentary insights of the three theoretical frameworks were formulated during anthropological fieldwork in various parts of Africa (Bourdieu 1958; Douglas 1963; Fiske 1985), and where then later transposed, and generalised, to (dare I say?) "more industrialised" societies.

2.12 Another fork in the road of the social sciences that the four scholars refuse to take consists of the usual split between those who assume that functional forces are at work within societies and those who assert that societies are conflict-ridden. The theory of practice, cultural theory and relational models theory all have a functionalist streak, in that these frameworks assume that social structures tend to produce the systems of collective thought that justify these very social structures (of course, with all the provisos for individual creativity, reflection and critique that I mentioned above). Yet these theories also view social life as characterised by an unceasing struggle between different groups of actors, each of which is trying to impose its preferred way of organising (and, therefore, of interpreting) society onto everyone else. Again, the language is different, but the message is quite similar:

Each state of the social world is thus no more than a temporary equilibrium, a moment in the 
dynamics through which the adjustment between distributions and incorporated or institutionalized classifications is constantly broken or restored. The struggle which is the very principle of the distributions is inextricably a struggle to appropriate rare goods and a struggle to impose the legitimate way of perceiving the power relations manifested by the distributions (Bourdieu 1990b: 41).

Cultural transmission is absolutely not a game of pass-the-parcel. Culture is a lively and responsive thing, more like a cat fight than a single solitary cat, a coherent flurry of contradictory bundles that are continually being negotiated and renegotiated in order to sustain and justify the preferred patterns of social relations that go along with them. And if, as we argue, social, political, and economic life is about the clash of these contradictory preferred patterns of relations -preferred ways of life- then there will be more than one cultural bias in any one society. The continuity of the whole (like the cat-fight) is sustained by the perpetual divergence of the parts. A consensus around customs does indeed exist the Brits eat roast beef and the French eat frogs's legs- but it is neither very interesting nor very instructive until and unless we connect these customs to continuity or change in ways of life. Cultural dissensus -the clash of cultural biases- is what we should be looking at and analyzing policies in terms of (Thompson and Wildavsky 1986: 170-71).

People are disposed to get angry and punish those who violate the models that they themselves are using, but the targets of such sanctions often do not acknowledge that that particular model applies, or that their acts were transgressions, so they perceive the intended sanctions as illegitimate aggression. This may launch rounds of mutual recrimination or violence (Fiske 2004a: 21).

2.13 And this immediately reveals the way in which these authors are able to reconcile a functionalist account with the assumption that social life is essentially antagonistic. Rather than assuming that the whole of society is dominated by a single way of organising and interpreting (as was often the case in previous social theories - see Thompson, Ellis and Wildavsky, part II), the authors assume that social situations typically comprise several antagonistic groups of actors adhering to rivalling ways of organising and perceiving.

2.14 Besides their shared ambition to not get impaled on the horns of a variety of long-standing social science-dilemmas, Bourdieu, Douglas and Thompson, and Fiske have developed other ideas that are strikingly similar as well. They all stress what Bourdieu (1977: 109-114) has labelled the "economy of logic", i.e., people's tendency to use a small number of cognitive schemes and templates to make sense of different parts of their lives. As cultural theorist Aaron Wildavsky (1987: 8) put it:

[Social filters] enable people who possess only inches of facts to generate miles of preferences.

\subsection{This is not far removed from Bourdieu's (1977: 110) assertion that:}

Practical logic -practical in both senses of the word-is able to organize the totality of an agent's thoughts, perceptions, and actions by means of a few generative principles...

\subsection{Or from the following observation by Alan Fiske:}

[A] few universal models can generate the great cultural diversity that we see around the world and through history (Fiske 1991a: 139).

2.17 In addition, all these authors dwell upon the symbolic roles that the human body plays in shaping society (Bourdieu 1977: 114-24; Douglas 1970; Fiske 1991a: 391-400), as well as chide neo-classical economics for acting as a scientific front for a particular ideology by presenting a socially constructed reality (namely, that of competitive markets and people) as a "natural", inevitable and all-pervasive state of affairs (Bourdieu 1977: 177; Douglas and Isherwood 1979; Fiske 1991b). Last, all these authors assert that the proper unit of analysis for social science is not made up of individual persons or organisations, but rather of systems of social relations. On this, once again, they seem to almost echo each other:

To speak like Cassirer (1923) in Substance and Function: one must think relationally. Now, it is easier to think in terms of realities that can be "touched with the fingers," in a sense, such as groups or individuals, than in terms of relations.... It is for the purpose of breaking with this substantialist mode of thinking, and not for the thrill of sticking a new label on old theoretical wineskins, that I speak of the "field of power" rather than of the dominant class, the latter being a realist concept designating an actual population of holders of this tangible reality that we call power. By field of power, I mean the relations of force that obtain between the social positions which guarantee their occupants a quantum of social force (Bourdieu in Bourdieu and Wacquant 1992: 228-30; emphasis added).

A final distinctive feature of our relational models theory approach to interpersonal cognition and behaviour is that its level of analysis and emphasis is relational rather than individual. (Fiske and Haslam 2005: 282; emphasis added).

We have now come to the most difficult, and most contentious, part of cultural theory: the counter-intuitive turning-away from the individual as the fundamental unit of attention.... The trick is to see the various forms of solidarity as the 'prime movers', each all the time trying to strengthen itself by encouraging more people to place more of their transactions, more of the 
time, on that pattern of social relationships and its sustaining cultural bias, while doing everything it can to put spokes in the wheels of the others. Preferences, in other words, are formed between people rather than within each of us, and values are stabilised not in the hearts and minds of individuals but by the kind of solidarity that they are developing at any one time. Individuals, however, do not disappear from the picture, nor do we have to see them as preprogrammed automata unquestioningly carrying out the actions that are specified by the solidarities of which they are the zombie-like components. Cultural theory does not deny individuality; all it does is systematically open up the implications of the unremarkable observation that individuality (as Elster nicely puts it) is, to a considerable extent, 'inherently relational' (Thompson, Grendstad and Selle 1999b: 12; emphasis added).

2.18 In sum, the theory of practice, cultural theory and relational models theory should be counted among the most exciting theoretical enterprises of the last three decades as they represent well-developed syntheses of many previously unsettled debates within the social sciences. These three syntheses are intriguingly similar in a variety of ways. This is not to argue, of course, that no differences exist between the frameworks. Their differences will come out in a discussion of their (relative) weaknesses and strengths.

\section{Shortcomings}

3.1 In particular in the light of cultural theory and relational models theory, the main weakness of Bourdieu's theory of practice seems to me to be clear: it lacks an explicit typology of basic, alternative forms of organising, justifying and perceiving social relations. Bourdieu's rejection of the need for, and possibility of, a classification of elementary social forms (e.g. Bourdieu 1984: 470) constitutes the main difference between his work and that of Douglas and Thompson, as well as that of Fiske. In cultural theory, five basic ways of organising social relations -each with distinctive perceptions of nature, human nature, risk, time, space, causality, leadership, etc.- are identified (Douglas 1978): individualism, egalitarianism, hierarchy, fatalism and the hermit. In relational models theory, four elementary structures for coordinating social relations are distinguished (Fiske 1991a): communal sharing, authority ranking, equality matching, and market pricing. In both these theories, the infinite social and cultural variety of the past and present is explained as the endless reinvention, and recombination, of a small set of fundamental forms of human interaction. In proposing these (quite similar) typologies, Douglas and Thompson, and Fiske, are again inspired by the canonical works of social and political science. Marx (1845/1972), Maine (1861/1986), Tönnies (1887/1991), Durkheim (1912/1985), Weber (1922/1980), Piaget (1932/1997), Benedict (1934/1989), among many others, were all convinced of the view that explanation and theory-building require typologies. Bourdieu (1984: 479), of course, acknowledges that:

What is at stake in the struggles [of the social world] is power over the classificatory schemes and systems which are the basis of the representations of the groups and therefore of their mobilization and demobilization.

3.2 However, he refuses to set out a clear classification of such groups - and their competing classificatory schemes. Thus, Bourdieu gets himself into various conceptual troubles.

3.3 The first of these troubles is that without a typology of alternative ways of organising human relations it becomes very difficult to explain social change. A classification enables one to conceive of social transformation as the waxing and waning, as well as splitting and merging, of alternative organisational and cognitive structures. (This would also open the possibility to combine social theory with complexity theory; for cultural theory, this is currently being done by Paul Tayler and Michael Thompson forthcoming). Without a taxonomy, it is hard to understand how social dynamics could be conceived of. As Bourdieu stresses the possibility for critical thinking, resistance and self-reflexivity, he leaves the door open for social change, but without any typology of ways of organising it remains unclear in which direction any change might then be headed.

3.4 In the absence of a clear typology of organisational and cognitive structures, it also becomes much more difficult to achieve one of Bourdieu's main theoretical aims, namely to facilitate self-reflexivity among social scientists. It is always difficult to recognise -let alone remove- the blinkers that impair one's vision (if that weren't the case, then these wouldn't be blinkers). But if one is armed with a typology of the ways in which people tend to think and act, then it becomes easier to realise from which perspective one is arguing, and on which fundamental assumptions one's perspective rests - and thus to start taking other viewpoints and concerns into account. For instance, if one applied the cultural theory to which political scientist Aaron Wildavsky has made significant contributions (Douglas and Wildavsky 1982; Thompson, Ellis and Wildavsky 1990) to his own efforts to influence specific public policies (e.g., Wildavsky 1988; Singer and Wildavsky 1993; Wildavsky 1995), then it becomes clear that he was almost invariably advocating individualistic policies. (In terms of relational models theory, Wildavsky was forever favouring more market pricing over other models of human interaction). However, in the theory of practice, each social field is a battleground for the struggle "to determine the conditions and criteria of legitimate membership and legitimate hierarchy" (Bourdieu 1988: 11). In other words, although Bourdieu portrays social life as a battle between groups that are adhering to alternative principles of legitimacy and classificatory schemes, he also depicts each of these alternatives as just another variant of an exploitative, exclusionary and hierarchical way of organising, perceiving and justifying social relations. In his view, each of the competing social groups or classes attempts to impose a particular moral and classificatory system that would ensure its own ascendancy in terms of status, material benefits and influence - at the expense of all others. As he puts it in Outline of a Theory of Practice (Bourdieu 1977: 164-65):

Every established order tends to produce (to very different degrees and with different means) 
the naturalization of its own arbitrariness. Of all the mechanisms tending to produce this effect, the most important and the best concealed is undoubtedly ... the correspondence between the objective classes and the internalized classes, social structures and mental structures, which is the basis of the most ineradicable adherence to the established order. Systems of classification which reproduce, in their own specific logic, the objective classes, i.e. the divisions by sex, age, or position in the relations of production, make their specific contribution to the reproduction of the power relations of which they are the product.

The taxonomies of the mythico-ritual system at once divide and unify, legitimating unity in division, that is to say, hierarchy.

Social representations of the different ages of life, and the properties attached by definition to them, express, in their own logic, the power relations between the age-classes, helping to reproduce at once the union and the division of those classes by means of temporal divisions tending to produce both continuity and rupture. They thereby rank among the institutionalized instruments of the symbolic order, and hence among the mechanisms of the reproduction of the social order whose very functioning serves the interests of those occupying a dominant position in the social structure.

3.5 And, therefore, in Homo Academicus (Bourdieu 1984: 11; emphasis added):

The university field is, like any other field, the locus of a struggle to determine the conditions and the criteria of legitimate membership and legitimate hierarchy, that is, to determine which properties are pertinent, effective and liable to function as capital so as to generate the specific profits guaranteed by the field. ... Thus there exists quite objectively a plurality of rival principles of hierarchisation, and the values, which they determine are incommensurate, or even incompatible, because they are associated with mutually conflicting interests.

3.6 From this perspective, seemingly benevolent, generous acts are not to be trusted, as these only serve to shore up the particular form of hierarchical oppression (i.e., the prevailing distribution of economic, symbolic, religious and cultural capital) that happens to dominate in a time and place. Even donations to hospitals and support for welfare policies are not to be taken at face value (Bourdieu 1990b: 133):

It is equally clear why the development of the capacity for subversion and critique that the most brutal forms of 'economic' exploitation have aroused, and the uncovering of the ideological and practical effects of the mechanisms ensuring the reproduction of the relations of domination, should bring about a return to modes of accumulation based on the conversion of economic capital into symbolic capital, with all the forms of legitimizing redistribution, public ('social' policies) and private (financing of 'disinterested' foundations, donations to hospitals, academic and cultural institutions, etc.), through which the dominant groups secure a capital of 'credit', which seems to owe nothing to the logic of exploitation.

3.7 In terms of cultural theory, Bourdieu perceives social life mainly as an eternal struggle between different versions of hierarchy - and only does so from the critical vantage point of egalitarianism. In the words of relational models theory, Bourdieu depicts the social world as a series of battles between groups favouring different forms of authority ranking. For instance, when Bourdieu writes of capitalism, education or the arts (Bourdieu et al. 1999; Bourdieu 1999; Bourdieu and Passeron 1977; Bourdieu 1984), then he merely attempts to uncover the systems of domination and oppression (the self-perpetuating distributions of economic, symbolic, cultural and religious capital) that underpin these forms of social life - and he remains silent on their many other conditions and characteristics (such as individual creativity, entrepreneurship, vibrancy, stewardship, or concern for others). At one point in his work, Bourdieu (1984: 470 ) appears to come close to recognising alternative forms of organising, perceiving and justifying social relations - only to argue again that these could not be anything else but different variations on domination and hierarchy:

And the recurrence of the triadic structure studied by Georges Dumézil, which Georges Duby shows in the case of feudal society to be rooted in the social structures it legitimates, may well be, like the invariant oppositions in which the relationship of domination is expressed, simply a necessary outcome of the intersection of the two principles of division which are at work in class-divided societies - the division between the dominant and the dominated and the division between the different fractions competing for dominance in the name of different principles.

3.8 In thus truncating social life to the struggle between alternative forms of repressive hierarchy, Bourdieu is unable both to recognise the possible useful functions that hierarchical ways of organising may have to fulfil in a peaceful, democratic and plural society (cf. Douglas 2005) and to explore the disadvantages and weaknesses of non-hierarchical forms of organising. Ironically, although Bourdieu sees his call for more self-reflexivity as his most important contribution to the social sciences (Bourdieu 1990b: 15; Bourdieu and Wacquant 1992), his own analysis does not allow for much self-reflexivity. This second line of criticism underscores my earlier point as well: as Bourdieu conceptualises social life as a never-ending struggle between different versions of repressive hierarchy, it is hard to see how fundamental social change could come about or could be explained.

3.9 The absence of an explicit typology of ways of organising human relations in the work of Bourdieu causes two additional problems. This lack of concreteness makes it quite difficult to falsify any part of the theory of practice - and this sits uneasily with Bourdieu's repeated calls for an objective, scientific analysis of social life. For example, how could one go about falsifying the claim that -in general- 
classificatory systems matter to the distribution of material goods and influence in society? Furthermore, the lack of concreteness renders the theory less useful as a basis for understanding how pressing social problems can be practically resolved. If seemingly genuine acts of solidarity (such as private gifts to hospitals or social welfare-programs) are to be understood merely as attempts to placate the dominated classes, then how to give concrete policy advice concerning public health, social security, environmental protection, and other pressing problems? How, to be very concrete, to judge for example the current efforts of Bill Gates -the wealthiest person on earth- to eradicate a variety of terrible diseases in the poorest parts of the world by founding a charity dedicated to these causes, and then donating 750 million U.S. dollars to it?

3.10 In my view, the Achilles heel of Alan Fiske's relational models theory concerns his typology of elementary forms of organising social relations. ${ }^{[5]}$ I am not convinced that it meets the standard demands for a useful classification, namely that the categories of the classification be jointly exhaustive as well as mutually exclusive. In particular, his fundamental modes of human interaction (communal sharing, authority ranking, equality matching, and market pricing) appear to be somewhat overlapping. Communal sharing is "characterized by the fact that people attend to group membership and have a sense of common identity, while the individuality of separate persons is not marked" (Fiske 1991a: 13), while people who engage in authority ranking "construe each other as differing in social importance or status" (Fiske 1991a: 14). So far, so good - these two "mods" appear clearly different. I believe that the overlap begins with the other two mods. Equality matching is "an egalitarian relationship among peers who are distinct but coequal individuals" (Fiske 1991a: 14-15), whereas market pricing denotes "a relationship mediated by values determined by a market system" (Fiske 1991a: 15). To me at least, it appears difficult to always unequivocally separate equality matching and authority ranking on the one hand, from communal sharing and market pricing on the other. For instance, in competitive markets (i.e., transactions that resemble the "ideal markets" of neo-classical economics), actors are certainly "equal, but distinct peers": none of them has more market power than any of the others, and none of them can hope to earn a higher wage, or make a larger profit, than the others. Yet, these markets not only fulfil the conditions of equality matching, but also of market pricing. Similarly, in many Japanese markets (Dore 1987), each major company is closely related -in an almost paternalistic way- to a set of smaller competitors, suppliers and retail firms. When profits and prices fall or cheaper alternatives become available, the large company at the centre of the network will not abandon the peripheral enterprises, but instead offer them advice as to how to reorganise their companies and even forms of temporary financial support. These practices constitute authority ranking and market pricing at the same time. In addition, whenever communal sharing results in a more or less equal allocation of goods, then it will be hard to differentiate this mod from that of equality matching. Last, as Edward Banfield (1958) has beautifully illustrated (cf., Putnam 1993), a particular form of equality matching is also prevalent when social relations are characterised by extreme levels of inter-personal distrust and jealousy. Under those circumstances -labelled "amoral familism" by Banfield- no cooperation will take place if anyone benefits more from the collective effort than the others. Fiske calls such relations "asocial relationships", and does not include them among his four models of human interaction (as they are more a model of obstructing human interaction). Still, a perverse form of equality matching is characteristic of such null relationships.

3.11 Fiske does not deny that his categories are partly overlapping. And he has proposed an elegant way out of this predicament by arguing that his four relational models should not be seen as mutually exclusive types, but rather as categories that are nested inside each other: each category is supposed to represent an increasingly complex form of organising human relations. The simplest way of interacting is communal sharing. A bit harder to do is authority ranking, while equality matching is even more difficult. And the most complicated form of organising social relations is represented by market pricing. This increasing complexity is reflected in the different types of measurement scales that are supposed to guide the various relational models (Fiske 1991a: 210-230). In communal sharing, the appropriate measurement scale is categorical/nominal. In authority ranking, decisions are made with the help of an ordinal scale, and in equality matching an interval scale is used. In market pricing, ratios guide decisions. These measurement scales are of course of increasing complexity - with the more complex scale incorporating all of the simpler ones. The idea that the mods are of increasing complexity also reappears in other parts of Fiske's theory. He argues (Fiske 1991a: 402-4) that children learn each of these forms of interacting consecutively, starting early on with communal sharing and ending relatively late in their childhood with market pricing. Moreover, he asserts (Fiske 2000) that the capacity to engage in these ways of coordinating has become ingrained in different stages of the evolution of human life. However interesting all this is, it also reinforces the criticism that Fiske's four relational models are not mutually exclusive. In particular in light of the fact that all four mods are supposed to be present within any social situation, this appears to reduce the applicability and clarity of relational models theory.

3.12 Cultural theory has its own drawbacks. One of these also pertains to its classification of fundamental ways of organising, justifying and perceiving social relations. This classification is clearly mutually exclusive and jointly exhaustive, as it is derived (Douglas 1978) from two independent dimensions of social interaction, usually called "grid" (the degree to which social relations are ranked and stratified) and "group" (the extent to which people feel bound to a larger unit than the individual). Assigning two values (high and low) to these two dimensions results in four distinct ways of organising (and justifying and perceiving) human relations: hierarchy (high grid, high group), individualism (low grid, low group), egalitarianism (low grid, high group) and fatalism (high grid, low group). A fifth way of life, that of the hermit, is then added by noting that while the other ways of life are all means of engaging in social interaction, people can also decide to withdraw from social life (Thompson 1982). Each social field is then supposed to consist of a never-ending waxing and waning, and merging and splitting, of these five "social solidarities" (to invoke Durkheim's old term). Although this typology has been remarkably successful -in particular in setting out the disagreements among people regarding a wide variety of public issues, from safety seat beltslegislation (Adams 1995) to the governance of the Internet (Tranvik and Thompson 2005) - it remains problematic that two continuous dimensions (grid and group) are used to produce four distinct ways of 
organising (and one way of avoiding) social relations. It would be more elegant for these two dimensions to be dichotomous. Hence, the search is still on for a proper definition of cultural theory's two central terms. ${ }^{6]}$

3.13 In addition, it is still not clear why, as cultural theory states and as has been confirmed by quite a bit of empirical research (e.g. Coyle and Ellis 1994), public debates are typically polarised between groups of people adhering to quite distinct and pure versions of the ways of organising and perceiving (whereas the social domains in which these people have to operate typically consist of ever-changing mixes of these ways of organising). How does this process of polarisation of opinion along the four lines set out by cultural theory take place? Why it is so easy to recognise individualistic, egalitarian, hierarchical and fatalistic voices in public debates - in particular when it seems clear that people's lives take place in many social domains that are typically mixes of the various ways of organising and thinking?

3.14 Last, I believe that cultural theory's initial "promise" -the very reason for which Douglas (1970; 1975; $1978 ; 1982$ ) set out to develop the approach- has not yet been fully delivered upon. In developing cultural theory, Douglas (1978: 15) explicitly aimed to construct a method that would enable comparisons across time and space, which would then facilitate the formulation and testing of novel explanations of such important social phenomena as nationalism, war, religion, poverty, genocide, etc. In my view, this challenge has only been partially taken up thus far. One interesting application of cultural theory has been to the field of leadership (Wildavsky 1984; Ellis and Wildavsky 1989), where it has deepened our understanding of which types of political and religious leadership are acceptable, and therefore successful, in different social settings. But perhaps the most impressive applications have been to the field of governance (Schwarz and Thompson 1991), where it has been established that public policies and business plans tend to fail if they are not based on a full consideration of all ways of organising and perceiving, as well as to the analysis of risk (Douglas and Wildavsky 1982; Thompson and Rayner 1998), where it has been shown that people's perceptions of risk are best predicted by their preferred ways of organising. Yet, the bulk of applications of cultural theory have remained confined to showing that it is possible to distinguish between egalitarian, hierarchical, individualistic and (at times) fatalistic voices in discourses on social issues. Douglas's clarion call -to construct, on the basis of the theory, alternative explanations of such vital social phenomena as nationalism, religion, revolution, famines, terrorism, etc.has thus far not been sufficiently heard, or acted upon. Much remains to be done in this regard (Coyle 1994).

\section{Strengths}

4.1 Each of these three theories, therefore, has its own, specific weaknesses. It is equally important to note that they all have their comparative strengths as well. In my view, Bourdieu's work distinguishes itself from the other two approaches in at least two ways. First, it sets itself apart by its insistence on the need for social science to be studied in a self-reflexive manner (i.e., to reflect critically and rigorously on both the social conditions for, and the social consequences of, social theorising itself). This, to me, remains a vital insight and practice that the social sciences should always incorporate. Second, Bourdieu's research stands out for having been applied to elucidate whole social fields, such as the French university system or the French cultural field. Such an ambitious endeavour has not been undertaken on the basis of cultural theory or relational models theory, and Bourdieu's work in this regard should function as an inspiration to do so.

4.2 Alan Fiske's relational models theory has been ground-breaking in forging links with a variety of sciences that are not usually considered when building social theory. Together with some of his UCLA colleagues (lacoboni et. al. 2004; Fiske 2005), he has been at the forefront of the efforts to bridge the gap between the social sciences and brain research. He has attempted to deepen our understanding of the human brain with the help of relational models theory, and, vice versa, to fortify his social theory with novel insights from neuroscience. Among other things, Fiske and his colleagues have suggested -on the basis of solid neuroscientific research- that being aware of, and cognising, social relations may well be the "default state" of the human brain, thus providing further ammunition to the social scientists who have sided with Aristotle in arguing that humans are first and foremost social beings. Closely related to these efforts, Fiske and his collaborators have begun to search for fruitful ways of linking social theory with evolutionary theory and studies of animal social complexity (Haslam 1997; Fiske and Fiske 2005). They have suggested that the human ability to engage in communal sharing may have been an extension of an early evolutionary trait, namely the bond between parents and offspring, whereas the human ability to engage in authority ranking (and other relational models) may have emerged at a later, more complex evolutionary stage. With the help of evolutionary theory, Fiske (2005) has begun to build the case for why people may be able to co-ordinate their mutual relations in not more than a handful of basic ways. Fiske has also pushed the envelope in having been the first one to link his social theory to childhood studies (arguing that children learn to interact according to different models at consecutive phases) and to the study of emotions (Fiske 2002). In addition to all this, Fiske has been one of the very few social scientists to confront one of the most basic, and perhaps most difficult, questions in the social science (Fiske 2004b): what is a "social relationship"? How do social relationships get constituted?

4.3 Specific praise can also be heaped upon the cultural theory developed by Mary Douglas and Michael Thompson. Apart from its more useful typology, it appears the one theory that has the clearest and most concrete implications for collective efforts to alleviate human suffering. As it argues and shows in detail (Schwarz and Thompson 1991; Hood 1998; Thompson, Grendstand and Selle 1999a) why policies that are not based on a full consideration of all the points of view that are advocated by the people and organisations involved tend to be self-defeating and to increase human misery, it offers yet another form of support for establishing human rights, democracy and deliberative decision-making. In addition, in particular Michael Thompson's efforts have linked cultural theory in elegant ways to the study of human complex systems (Tayler and Thompson 1986; Tayler and Thompson forthcoming), ecology (Thompson 1996) and technology studies (Tranvik, Selle and Thompson 2000). Thus, he has been able to sketch the 
contours of a theory in which social, ecological and technological forces constantly interact in unpredictable, though not random, ways (Thompson 2002).

\section{Summing Up}

5.1 I believe that by combining these three frameworks, we may be able to arrive at a social theory that is cumulative, parsimonious, relevant to collective efforts to alleviate pressing social problems, in support of human rights, and linked in interesting ways to relatively novel fields in the natural sciences (including social neuroscience, the study of animal social complexity, ecology and non-linear mathematics). This may seem a very distant goal, but I think that the analyses of Pierre Bourdieu, Mary Douglas and Michael Thompson, and Alan Fiske have already brought us a considerable distance. In showing that there are solutions to many of the long-standing disputes in the social sciences, they have helped us overcome a number of the obstacles that have tripped up previous attempts at building social and political theory. Moreover, by picking and mixing the most appealing features of these three approaches, we can get ourselves even further on our way. I will conclude by sketching my favourite conceptual brew, which I propose to call "a theory of constrained relativism".

5.2 Besides all the elements that are shared by the theory of practice, cultural theory and relational models theory, I would advocate selecting the five-fold typology that has been developed by Mary Douglas and Michael Thompson - with the proviso that the underlying dimensions would have to be further clarified. Without a typology there can be no theory. Although this statement appears a commonplace, banality even, among natural scientists, and was also unquestioned by the "grand" social scientists of yesteryear, in my experience it often comes as a surprise to today's sociologists, anthropologists, economists and political scientists. Yet, consider the following description of theory by Milton Friedman (1953: 53). In his view, theory shows:

that there is a way of looking at or interpreting or organizing the evidence that will reveal superficially disconnected and diverse phenomena to be manifestations of a more fundamental and simple structure.

5.3 This elegant description immediately reveals the importance of a typology (Friedman's "simple structure") for theorising. Selecting the classification of Douglas and Thompson would ensure that any attempt at building a general social theory would be cumulative, as the classification has been carefully derived from many earlier attempts at categorisation. This applies to the rather similar classification proposed by Alan Fiske as well. However, the Douglas's typology has the added advantage of being mutually exclusive as well as jointly exhaustive. Moreover, more than any other typology, cultural theory's classification has proven its mettle in sorting out the alternative perspectives that typically separate the contenders in public debates about pressing social ills. And it has served as the basis for the (by now, reasonably well-tested) hypothesis that collective efforts to alleviate such ills will tend to fail -according to a diversity of norms and goals - if any of these alternative perspectives (and their adherents) are excluded from decision-making. Thus, by settling for cultural theory's typology, we would also ensure that social theory would be relevant for those who are interested in helping to ease the many ills afflicting the world, and that it would be on the side of preserving and extending human rights (as only this would ensure an open and plural debate among advocates of opposing perspectives). Last, as Michael Thompson's work has illustrated (Tayler and Thompson 1986; forthcoming), it would open up the possibility to link social theory with chaos and complexity theory, in an attempt to explore how the never-ending interactions between relatively simple and predictable behavioural strategies result ever-changing and unpredictable social and natural worlds.

5.4 The next elements that I would propose to add to a theory of constrained relativism would consist of the seminal work by Alan Fiske and his colleagues on the human brain, human evolution, and childhood learning. In particular their contributions to social neuroscience and evolutionary theory appear to me to be quite compatible with cultural theory, as this neuroscientific work has thus far mainly focused on two relational models: communal sharing and authority ranking. If one aims to combine relational models theory and cultural theory, this is intriguing as communal sharing and authority ranking are defined in such a way as to come very close to the two dimensions that underpin the typology of Douglas and Thompson: group, and grid, respectively. ${ }^{[7]}$ This resemblance suggests that the ongoing research of Fiske and colleagues on the (evolution of) the human brain may be compatible with, or at least be replicable for, cultural theory. Apart from providing further insights into the neural and evolutionary bases of different ways of interacting with others, this ongoing research holds out the hope that it will become possible to explain why human beings may only be able to organise their mutual relations in a limited set of ways. Such an explanation would have to be a central element of any theory of constrained relativism.

5.5 The finishing touches would be provided by Bourdieu's theory of practice. Bourdieu's emphasis on making a scientific analysis of the conditions and consequences of scientific analysing a part of any scientific enterprise should be heeded. In addition, through following Bourdieu's efforts to analyse whole social domains, it may be possible to construct the alternative explanations of important social and political phenomena that Douglas has called for.

5.6 Again, I would not want to suggest that it would be an easy task to construct a social and political theory that is cumulative, parsimonious, self-reflexive, policy-relevant and grounded in brain research and evolutionary studies; far from it - not even through combining the theory of practice, cultural theory and relational models theory. But, at least for me, perhaps the most important legacy of the writings of Pierre Bourdieu is the conviction that one should not shirk away from attempting to resolve the enduring puzzles of social science, and from addressing the pressing social and political questions of today. 


\section{Acknowledgments}

I gratefully acknowledge the support of the Office of Research of the Singapore Management University which funded this research.

\section{Notes}

${ }^{1}$ And, of course, their collaborators, such as, respectively: Luc Boltanski and Loïc Wacquant; Aaron Wildavsky and Steve Rayner; and Nick Haslam, among many others.

${ }^{2}$ Mary Douglas and Michael Thompson have hardly published together, though they know each other well (indeed, Douglas was Thompson's Ph.D. supervisor at the University College London.). An excellent overview of the different contributions that each of these two anthropologists has made to cultural theory is Mittleton-Kelly 2004.

${ }^{3}$ However, before I continue, I feel that I should heed Bourdieu's frequent injunction to be (publicly) selfreflexive, by pointing out that I can hardly be called a neutral arbiter of these three frameworks: I feel very fortunate that for quite some years now I have been able to collaborate and correspond with Mary Douglas and Michael Thompson, while I have also greatly benefited from having been in frequent contact with Alan Fiske. Almost needless to write, this article represents my views only.

${ }^{4}$ Some of the main publications are (respectively): Coleman 1990; Habermas 1997; Foucault 1980; Derrida 1980; Wallerstein 2004; Beck 1986; and Luhmann 2001.

${ }^{5}$ The original statement of Alan Fiske's relational models theory, Structures of Social Life (Fiske 1991), can be criticized on other grounds as well. This is done quite well in Turner (1992) and Whitehead (1993), where it is argued (among other things) that the theory misses an account of social conflict. However, since the publication of this book, Fiske and his collaborators have risen to these challenges by extending the original theory in interesting ways (Fiske 2004: 20-25). Conflict is now explained in two ways: as a clash between people favouring alternative (combinations of) mods; and as the excessive adherence to a single mod in a particular situation (Fiske and Tetlock 1997; Haslam 2004).

${ }^{6}$ For this reason, Michael Thompson (1996) has proposed two other dimensions: "accountability" instead of group, and "symmetry" instead of grid. However, I am neither convinced that these dimensions are dichotomous, nor believe that these dimensions can be easily operationalised.

${ }^{7}$ Fiske (2004a: 4) defines communal sharing as "the mod that bases sociality on the perception that set of persons have something in common - something that makes them socially equivalent in some respect" And he describes (2004a: 5) authority ranking as "the mod that bases sociality on asymmetrical differences. [P]eople using this mod must complete it with socially transmitted preos which define how to rank people: by age, gender, caste, seniority, promotion system, achievement on a task or test, contest or combat, passage through a ritual, possession of symbolic paraphernalia, bestowal of fiefdom, position determined by divination or revelation, charismatic performance, religious devotion, election, delegation or appointment by higher authority". Compare this to Douglas, who defines (douglas 1978: 7) group" as "a measure of social incorporation", and who describes (1978: 8) grid as the extent to which there is: "an explicit set of institutionalised classifications [that] keeps [people] apart and regulates their interactions... The grid is visible in the segregated places and times and physical signs of discriminated rank, such as clothing and food".

\section{References}

ADAMS, John. 1995. Risk. London: University College Press.

BANFIELD, Edward. 1958. The Moral Basis of a Backward Society. New York: The Free Press.

BECK, Ulrich. 1986. Risikogeselsschaft: Auf dem Weg in eine andere Moderne. Frankfurt: Suhrkamp.

BENEDICT, Ruth. 1934/1989. Patterns of Culture. Boston, MA: Houghton Mifflin.

BOURDIEU, Pierre. 1958. Sociologie de I'Algérie. Paris: Presses Universitaires de France.

BOURDIEU, Pierre. 1977. Outline of a Theory of Practice. Cambridge: Cambridge University Press.

BOURDIEU, Pierre. 1984. Distinction: A Social Critique of the Judgment of Taste. London: Routledge.

BOURDIEU, Pierre. 1988. Homo Academicus. Stanford, CA: Stanford University Press.

BOURDIEU, Pierre. 1990a. In Other Words: Essays towards a Reflexive Sociology. Cambridge: Polity Press.

BOURDIEU, Pierre. 1990b. The Logic of Practice. Stanford, CA: Stanford University Press.

BOURDIEU, Pierre. 1999. Acts of Resistance: Against the Tyranny of the Market. London: New Press. 
BOURDIEU, Pierre, and Jean-Claude Passeron. 1977. Reproduction in Education, Society and Culture. London: Sage.

BOURDIEU, Pierre, Priscilla Parkhurst Ferguson, Susan Emanual, Joe Johnson, Shoggy T. Waryn, Alain Accardo. 1999. The Weight of the World: Social Suffering in Contemporary Societies. Stanford, CA:

Stanford University Press.

BOURDIEU, Pierre, and Loïc Wacquant. 1992. An Invitation to Reflexive Sociology. Chicago, IL: The University of Chicago Press.

COLEMAN, James S. 1990. Foundations of Social Theory. Cambridge, MA: Harvard University Press.

COYLE, Dennis J. 1994. The Theory that Would Be King. In Politics, Policy and Culture, edited by Dennis J. Coyle and Richard J. Ellis. Boulder, CO: Westview Press.

COYLE, Dennis J., and Richard J. Ellis, eds. 1994. Politics, Policy and Culture. Boulder, CO: Westview Press.

DERRIDA, Jacques. 1980. Writing and Difference. Chicago, IL: University of Chicago Press.

DORE, Ronald. 1987. Taking Japan Seriously: A Confucian Perspective on Leading Economic Issues. Stanford, CA: Stanford University Press.

DOUGLAS, Mary. 1963. The Lele of Kasai. Oxford: Oxford University Press.

DOUGLAS, Mary. 1966. Purity and Danger: An Analysis of the Concepts of Pollution and Taboo. London: Routledge.

DOUGLAS, Mary. 1970. Natural Symbols. London: Routledge.

DOUGLAS, Mary. 1975. Implicit Meanings. London: Routledge.

DOUGLAS, Mary. 1978. "Cultural Bias." London: Royal Anthropological Institute of Great Britain and Ireland.

DOUGLAS, Mary. 1987. How Institutions Think. London: Routledge.

DOUGLAS, Mary. 1992. Risk and Blame: Essays in Cultural Theory. London: Routledge.

DOUGLAS, Mary., ed. 1982. Essays in the Sociology of Perception. London: Routledge.

DOUGLAS, Mary, and Baron Isherwood. 1979. The World of Goods: Towards an Anthropology of Consumption. London: Routledge.

DOUGLAS, Mary, and Aaron Wildavsky. 1982. Risk and Culture: An Essay on the Selection of Technical and Environmental Dangers. Berkeley, CA: The University of California Press.

DURKHEIM, Émile. 1985. The Elementary Forms of Religious Life. New York, Basic Books.

ELLIS, Richard J., and Aaron Wildavsky. 1989. Dilemmas of Presidential Leadership: From Washington through Lincoln. New Brunswick, NJ: Transaction.

FISKE, Alan Page. 1985. Making up Society: Four Models for Constructing Social Relations among the Moose of Burkina Faso. Ph.D. dissertation in the Committee on Human Development, Departmental of Behavioral Sciences, University of Chicago.

FISKE, Alan Page. 1991a. Structures of Social Life: The Four Elementary Forms of Human Relations. New York: The Free Press.

FISKE, Alan Page. 1991b. The Cultural Relativity of Selfish Individualism: Anthropological Evidence that Humans Are Inherently Social. In: Review of Personality and Social Psychology, edited by M. Clark. Bevery Hills, CA: Sage.

FISKE, Alan Page. 1993. Social Errors in Four Cultures: Evidence about Universal Forms of Social Relations. Journal of Cross-Cultural Psychology 24, 4: 463-94.

FISKE, Alan Page. 2000. Complementary Theory: Why Human Social Capacities Evolved to Require Cultural Complements. Personality and Psychology Review 4: 76-94.

FISKE, Alan Page. 2002. Moral Emotions Provide the Self-Control to Sustain Social Relationships. Self and Identity 1: 169-75.

FISKE, Alan Page. 2004a. Relational Models Theory 2.0. In: Relational Models Theory: A Contemporary Overview, edited by Nick Haslam. London: Lawrence Erlbaum.

FISKE, Alan Page. 2004b. Four Modes of Constituting Relationship. In: Relational Models Theory: A 
Contemporary Overview, edited by Nick Haslam. London: Lawrence Erlbaum.

FISKE, Alan Page. 2005. Social Relations: Culture, Development, Natural Selection, Cognition, the Brain and Pathology. In Bridging Social Psychology, edited by P.A.M. van Lange. London: Lawrence Erlbaum.

FISKE, Alan Page, and Susan T. Fiske. 2005. Social Relations in Our Species and Our Cultures. In: Handbook of Cultural Psychology, edited by S. Katayama and D. Cohen. New York: Guilford.

FISKE, Alan Page, and Nick Haslam. 2005. The Four Basic Social Bonds: Structures for Coordinating Interaction. In: Interpersonal Cognition, edited by Mark W. Baldwin. New York: Guilford.

FISKE, Alan Page, and Philip Tetlock. 1997. Taboo Tradeoffs: Reactions to Transactions that Transgress Spheres of Exchange. Political Psychology 17: 255-294.

Foucault, Michel. 1994. The Order of Things: An Archaeology of Human Sciences . New York: Vintage.

FRAZER, Sir James George. 1922/1995. The Golden Bough: A Study in Magic and Religion. New York: Touchstone.

FRIEDMAN, Milton. 1953. Essays in Positive Economics. Chicago, IL, University of Chicago Press.

HABERMAS, Jürgen. 1997. Theorie des kommunikativen Handelns. Frankfurt: Suhrkamp.

HASLAM, N. 1997. Four Grammars for Primate Social Relations. In Evolutionary Social Psychology, edited by J. Simpson and D. Kenrick. London: Lawrence Erlbaum.

HASLAM, N. 2004. A Relational Approach to the Personality Disorders. In: Relational Models Theory: A Contemporary Overview, edited by Nick Haslam. London: Lawrence Erlbaum.

HIRSCHMAN, Albert O. 1992. The Concept of Self-Interest: From Euphemism to Tautology. In Albert O. Hirschman, Rival Views of Market Society and Other Essays. Cambridge, MA: Harvard University Press.

HOOD, Christopher. 1998. The Art of the State: Culture, Rhetoric and Public Management. Oxford: Clarendon Press.

IACOBONI, Marco, Matthew D. Lieberman, Barbara J. Knowlton, Istvan Molnar-Szakacs, Mark Moritz, C. Jason Throop, \& Alan P. Fiske. 2004. Watching Social Interactions Produces Dorsomedial Prefrontal and Medial Parietal BOLD fMRI Signal Increases Compared to a Resting Baseline. Neurolmage 21: 1167-73.

LUHMANN, Niklas. 2001. Soziale Systeme. Frankfurt: Suhrkamp.

MAINE, Henry S. 1861/1986. Ancient Law. Phoenix: University of Arizona Press.

MARX, Karl. 1845-86/1972. The German Ideology. In The Marx-Engels Reader, edited by Robert C. Tucker. New York: Norton.

MITTLETON-KELLY, Eve. 2004. The Information Systems Professional as a Hermit: Of Plural Rationalities, Information Rejection and Complexity. Innovation: The European Journal of Social Science Research 17, 4: 289-323.

PIAGET, Jean. 1932/1997. The Moral Judgment of the Child. New York: The Free Press.

PUTNAM, Robert D. 1993. Making Democracy Work: Civic Traditions in Modern Italy. Princeton, NJ: Princeton University Press.

SCHWARZ, Michiel, and Michael Thompson. 1990. Divided We Stand: Redefining Politics, Technology and Social Choice. Hemel Hempstead: Harvester Wheatsheaf.

SEN, Amartya K. 1977. Rational Fools: A Critique of the Behavioral Foundations of Economic Theory. Philosophy and Public Affairs 6, 4: 317-44.

SINGER, Max, and Aaron Wildavsky. 1993. The Real World Order: Zones of Peace, Zones of Turmoil. Chatham, NJ : Chatham House.

TAYLER, Paul, and Michael Thompson. Thompson, M. and Tayler, P. (1986), The Surprise Game: An Exploration of Constrained Relativism, Warwick, Warwick Papers in Management.

TAYLER, Paul, and Michael Thompson. Thompson, M. and Tayler, P. Forthcoming. The Forces that Cause Movement.

THOMPSON, Michael. 1980. Fission \& Fusion in Nuclear Society. Royal Anthropological News 41: 1-5.

THOMPSON, Michael. 1982. The Problem of the Centre: An Autonomous Cosmology', in Essays in the Sociology of Perception, edited by Mary Douglas. London, Routledge.

THOMPSON, Michael. 1984. Among the Energy Tribes: A Cultural Framework for the Analysis and Design of Energy Policy. Policy Sciences 17, 3: 321-39. 
THOMPSON, Michael. 1996. Inherent Relationality: An Anti-Dualist Approach to Institutions, University of Bergen, Norway: LOS Centre.

THOMPSON, Michael. 2002. Man and Nature as a Single but Complex System. In Encyclopedia of Global Environmental Change, Vol. 5: Social and Economic Dimensions of Global Environmental Change, edited by Peter Timmerman. Canada, Wiley.

THOMPSON, Michael, Gunnar Grenstad and Per Selle, eds. 1999a. Cultural Theory as Political Science. London: Routledge.

THOMPSON, Michael, Gunnar Grendstad and Per Selle. 1999b. Cultural Theory as Political Science. In: Cultural Theory as Political Science, edited by Michael Thompson, Gunnar Grendstad and Per Selle. London, Routledge.

THOMPSON, Michael, Richard Ellis and Aaron Wildavsky. 1990. Cultural Theory. Boulder, CO: Westview Press.

THOMPSON, Michael, and Steve Rayner. 1998. "Risk and Governance; Part I: The Discourses of Climate Change." Government \& Opposition 33, no. 2: 139-66.

THOMPSON, Michael, and Aaron Wildavsky. 1986. A Poverty of Distinction: From Economic Homogeneity to Cultural Heterogeneity in the Classification of Poor People. Policy Sciences 19: 163-99.

TÖNNIES, Ferdinand. 1887/1991. Gemeinschaft und Gesellschaft. Darmstadt: Wissenschaftliche Buchgesellschaft.

TRANVIK, Tommy, Michael Thompson and Per Selle. 2000. "Doing Technology (and Democracy) the PackDonkey's Way: The Technomorphic Approach to ICT Policy." In Governance of Global Networks in the Light of Differing Local Values, edited by Christoph Engel/Kenneth H.Keller. Baden-Baden: Nomos.

TURNER, Jonathan H. 1992. Book Review of Structures of Social Life. Contemporary Sociology 21: 12628.

WALLERSTEIN, Immanuel. 2004. World-Systems Analysis: An Introduction. Durham, NC: Duke University Press.

WEBER, Max. Wirtschaft und Gesellschaft. 1922/1980. Tübingen: Mohr.

WHITEHEAD, Harriet. 1993. Morals, Models, and Motives in a Different Light: A Rumination on Alan Fiske's Structures of Social Life. Ethos 21: 319-56.

WILDAVSKY, Aaron. 1984. The Nurturing Father: Moses as a Political Leader. Tuscaloosa, AL: The University of Alabama Press.

WILDAVSKY, Aaron. 1987. "Choosing Preferences by Constructing Institutions." American Political Science Review 81, no. 1: 3-21.

WILDAVSKY, Aaron. 1988. Searching for Safety. New Brunswick, NJ: Transaction.

WILDAVSKY, Aaron. 1995. But Is It True? A Citizen's Guide to Environmental Health and Safety Issues . Cambrige, MA: Harvard University Press. 